\title{
International Unit per Kilogram per Hour
}

National Cancer Institute

\section{Source}

National Cancer Institute. International Unit per Kilogram per Hour. NCI Thesaurus. Code C71209.

A dose calculation unit equal to one international unit (an arbitrary unit of biological activity) of a product per one kilogram of body mass administered per unit of time equal to one hour. 